\title{
Dynamics Mechanism of Vulnerability for Petroleum Enterprises
}

\author{
Zhirong Zhang ${ }^{1}$, Lichun Hou ${ }^{1,}{ }^{*}$, Zhenshan Lin $^{2}$, Weihua Guan ${ }^{2}$, Huiyu Liu ${ }^{2}$, Fanyuan Zeng ${ }^{1}$ \\ ${ }^{1}$ School of History Geography and Tourism, Shangrao Normal University, Shangrao, China \\ ${ }^{2}$ School of Geographic Science, NanJing Normal University, Nanjing, China
}

Email address:

houlchjs@163.com (Lichun Hou)

${ }^{*}$ Corresponding author

\section{To cite this article:}

Zhirong Zhang, Lichun Hou, Zhenshan Lin, Weihua Guan, Huiyu Liu, Fanyuan Zeng. Dynamics Mechanism of Vulnerability for Petroleum Enterprises. International Journal of Economy, Energy and Environment. Vol. 6, No. 1, 2021, pp. 11-17. doi: 10.11648/j.ijeee.20210601.12

Received: January 17, 2021; Accepted: February 2, 2021; Published: February 10, 2021

\begin{abstract}
This article analyses the dynamics mechanism of international petrochemical enterprises vulnerability and select the key factor of resources to establish a nonlinear dynamical model, which discovering the internal binding relationship between the number of big petrochemical enterprises vulnerability, the petroleum shortage ratio $(D)$ and the petroleum occupancy ratio of the biggest enterprise $(q)$. The results show that, as $D>q$, the petroleum shortage ratio exceeds the occupancy ratio of the biggest international petrochemical enterprise in the international petroleum resource market, the following rules and characteristics exist in the evolution of petrochemical enterprises:(1) The biggest enterprise in the petrochemical system will inevitably decline. With petroleum shortage increasing, following the decline of the biggest petrochemical enterprise will be the second, the third-biggest petrochemical enterprises and so on. The number of big decline petrochemical enterprise will increase with the increase of the value of $D / q$. The time for the petrochemical enterprises to go decline will be from 50 to 500 days. (2) After an incident of petroleum shortage, the surviving petrochemical enterprises will go through three stages: (A) resisting stage. (B) resumption stage. (C) stable stage. The international petrochemical industry will strictly observe the even-odd or odd-even number symmetry law. If the shortage of petroleum leads to the decline of odd-number petrochemical enterprises, after the adaptability and stability, the petrochemical enterprise system will obey the even-odd number symmetry law, i.e. the former ordinal number petrochemical enterprises become bigger. If the decline petrochemical enterprise in this system is ranked even-number, after the adaptability and stability, the petrochemical enterprise will obey the odd - even number symmetry law, i.e. the former odd numbered petrochemical enterprise become bigger, but those former even numbered get smaller. We think that a petrochemical enterprise will continually develop and grow stronger in the petroleum competition, only if it seizes the petroleum shortage ratio and the occupancy of the biggest enterprise in the petroleum resource market, understands the even-odd or odd-even number symmetry law in the petroleum economical system and positions itself correctly.
\end{abstract}

Keywords: Petrochemical Enterprise, Vulnerability, Mathematical Model, Dynamic Mechanism, Petroleum Shortage Ratio

\section{Introduction}

In the 20st century, the petrochemical industry made great contributions to the human living and development. Regardless of the developed country or the developing country, petrochemical industry has been the main industry of many national economics [1-3]. However, in the 21st century the humans may face the resources crisis, especially petroleum resources shortage [4-7]. The petroleum shortage may partially result in the decline and bankrupt of petrochemical enterprises.
It has been an indisputable fact, however, that the internal mechanism by which petroleum shortage brings about the partial decline of petrochemical enterprises and the new structure has not been fully recognized by the managers [8]. At present, although there are many studies in this respect, none is related to the internal dynamic mechanism between petroleum shortage and the bankrupt of petrochemical enterprises.

When examining the development process of petroleum companies from the perspective of system science, it can be found that petroleum companies are highly open in a market economy environment and belong to a complex economic system 
organization that can exchange resources and information with the external environment. The petroleum enterprise system will form a kind of diffusion force in the process of resource consumption. The strength of its ability directly determines the efficiency of the petroleum enterprise system in the use of resources, which indirectly reflects the resource consumption rate of the petroleum enterprise system. For this complex system, its operating status will be greatly affected by the internal and external resource environment of the petroleum enterprise system, and any slight disturbance of the resource environment may cause a huge change in the economic system of the petroleum enterprise. This is exactly the vulnerability characteristics of the petroleum enterprise complex system [9]. As it is affected by many uncertain factors, and in order to reduce or lessen the investment risk of enterprises and improve the scientific approach to decision-making, it is of great significance to construct an efficient early risk warning system for resource-based enterprises [10].

Because of the difficulty of nonlinear mathematics, the binding relation and the dynamical mechanism has not been much studied by the international economists. The difficulties in the math mainly owe to the fact that the petroleum economical system is a very complicated nonlinear system. With the development of the nonlinear science and math, the quantitative study and the dynamical mechanism study have gone deep into the geography, environment science, chemical industry science and economics [11-13]. Only by profoundly understanding the internal dynamics relation and developing mechanism between the administrative objects, can an enterprise grow in strength in the international competition [14]. Therefore, it is necessary to study the internal relationship between the petroleum shortage and decline of the international petrochemical enterprise.

A nonlinear dynamics model of the petrochemical enterprise competition in the petroleum economical system is given in Section 2. In Section 3, this model is used to simulate the dynamics of the relationship between the petroleum shortage and the decline of the petrochemical enterprise, and some applications are given in Section 4.

\section{The Competitive Model of Petrochemical Enterprise}

Supposing all the needed petroleum to maintain the international petrochemical system's normal production is one unit. $p_{i}$ (less than 1 , but more than 0 ) is the occupancy of petrochemical enterprise $i$ in the petroleum resource market; $c_{i}$ is the ratio that the petrochemical enterprise $i$ scrambles for from the petroleum source of other petrochemical enterprise, which is the capability of opening up to the petroleum market; $m_{i}$ is the internal decline ratio of the petrochemical enterprise $i ; D$ is the petroleum shortage ratio in the global petroleum economical system and $q$ is the occupancy of the biggest international petrochemical enterprise in the international petroleum resource market.

Based on mathematical modeling, after the shortage of the petroleum in the international petroleum resource market, the petroleum market and resource occupancy of the petrochemical enterprise $p_{i}$ changes with the time. If $p_{i}$ decrease to zero as time increases, the petrochemical enterprise $i$ will go decline. Conversely, if as time goes on, $p_{i}$ increases, then it means that the petrochemical enterprise $\mathrm{i}$ will grow in strength. Because $p_{i}$ has something to do with its competitive capability and the internal decline ratio $m_{i}$, petrochemical enterprise are ranked from the best competitor for a limiting resource to the poorest. The following hypothesis is given:

(1) All the petrochemical enterprises have equal internal decline ratio $m_{i}$;

(2) Before the global shortage of the petroleum resources in the international market, the occupancy $p_{i}$ disperses as geometric series.

(3) Because the surplus market $(1-q)$ is still large, it is easier for the small enterprise to open up its market. We assume the capability that the enterprise opens up the market disperses as geometric series:

$$
m_{i}=m ;\left.\quad p_{i}\right|_{D=0}=q(1-q)^{i-1}, \quad c_{i}=m_{i} /(1-\mathrm{q})^{2 i-1}
$$

Using the metapopulation model as a reference [15-16], we propose the petrochemical enterprise competitive dynamics model under the global resources market economics as following:

$$
\frac{d p_{i}}{d t}=c_{i} p_{i}\left(1-D-\sum_{j=1}^{i} p_{j}\right)-m_{i} p_{i}-\sum_{j=1}^{i-1} p_{i} c_{j} p_{j} \quad i=1,2 \ldots n
$$

The terms on the right are, respectively, the reproduction, internal decline and loss in the petroleum-market due to competitive displacement.

\section{The Dynamics Mechanism of Decline of the Big Petrochemical Enterprises When $\mathbf{D}>\mathbf{q}$}

\subsection{Dynamics Simulation}

Dynamics simulation (Figure 1) of the models (1)-(2) reveal the dynamics of the decline of the big petrochemical enterprises in the international petrochemical market: (1) Because $D=0.2$ is far more than $q=0.03$, it means that the petroleum shortage ratio is comparatively very large, the biggest petrochemical enterprise in the international petrochemical enterprises will inevitably go into liquidation. The delay time for the decline of the biggest petrochemical enterprise $n 1$ is about 300 to 360 days. (2) Following the biggest petrochemical enterprise, the order of the decline of other petrochemical enterprises will be the second, the third and the fourth biggest petrochemical enterprise and so on. When $D>q$, the big petrochemical enterprise will precede the small petrochemical enterprise in closing. (3) After going through the severe attack of petroleum shortage, the surviving petrochemical enterprises will come through three developing adaptive stages: (a) The stage of compelled adaptation or resistance: In a short time of petroleum shortage $(1 / \mathrm{m})$, the 
petroleum occupancy of all the petrochemical enterprises will drop sharply. But the falling range of the weaker enterprises will be relatively smaller because they have stronger resistance; (b) The resumption stage: This is a very complicated nonlinear interaction stage of the multiple petrochemical enterprises competition. It is the multi-equilibrium state of coexistence in the international petrochemical system and the constant substitution of the bigger petrochemical enterprise by the next smaller in a continuous manner at different phases. The resumption stage clearly shows frequent substitution of the sectional big petrochemical enterprise and the competition is very intense and cruel. (c) The stable stage: After a long process of evolution, the system will achieve a new equilibrium state. After the first four big petrochemical enterprises respectively go decline in turn, then $\mathrm{n} 5, \mathrm{n} 7$, (not n6) will respectively be the first biggest and the second biggest.

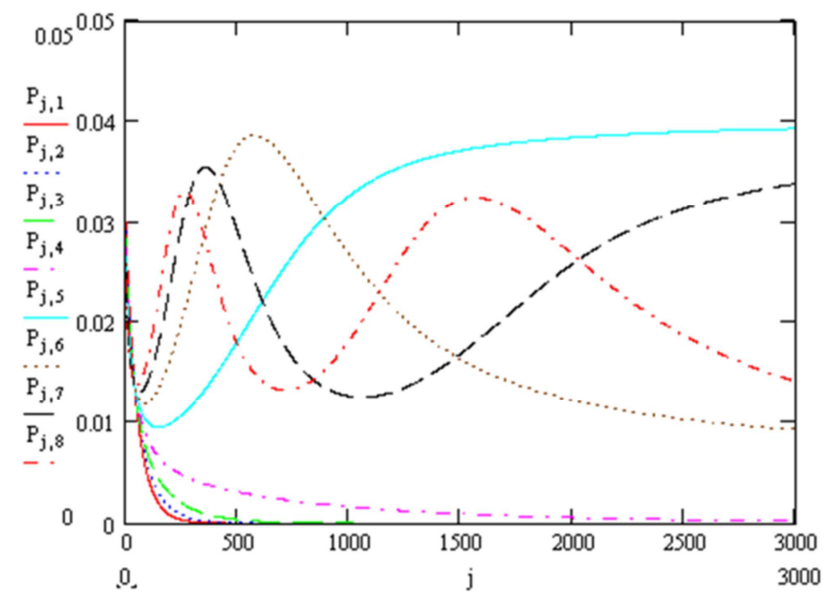

Figure 1. The relatively severe petroleum shortage induces the first four international petrochemical enterprises to go decline. In it, the parameter adopted are: $D=0.20, q=0.03, m=0.1, n=8$.

We think, when the petroleum shortage rate $D$ is more than some value, the big petrochemical enterprise goes decline firstly instead of the small one as be expected. It is because: Looking from the competitive mechanism among the petrochemical enterprises, the big petrochemical enterprise has very strong dependence on the petroleum resource market, owing relative lower capability to open up to new market. While the smaller petrochemical enterprise has the higher capability to open up to new market. So they can survive in the petroleum crisis. Because any big petrochemical enterprise has limited resistance to the petroleum crisis, as soon as the petroleum shortage exceeds its resistance limit, the internal self-regulation ability will rapidly fall and disappear, that will lead the big petrochemical enterprise to go decline. But the small petrochemical enterprises have stronger resilience and adaptability, so they can adapt to new petroleum situation quickly and survive from getting drowned.

Figure 1. clearly shows that: (1) The small industries take the first place of the international petrochemical enterprises circles by turn (petroleum occupancy exceeds 0.03 ) in the resumption stage (transition state). It means a revolutionary change for the international petrochemical enterprises circle (the price to pay is the first four biggest petrochemical enterprises' decline). (2)
The original biggest petrochemical enterprise $\mathrm{n} 1$ has the petroleum occupancy of 0.03 , but enterprises $n 5, \mathrm{n} 7$ increase their occupancy to $0.04 /(1-0.2)=0.05$ and $0.037 /(1-0.2)=0.046$ in the new equilibrium state. It is visible that after the petroleum crisis, the international petrochemical enterprises system is concentrative and monopolistic enough to cope with a new possible petroleum crisis. The resistance to the petroleum shortage by the petrochemical enterprises circles has greatly increased. (3) The smallest petrochemical enterprise n8 becomes the biggest petrochemical enterprise of the system after the 250 days of the petroleum shortage, the period for $n 7$ is 350 days, $n 6$ is 550 days, n5 is 1000 days. But the stable biggest survivor in the international petrochemical enterprises system is n5. (4) The strong-weak order of the petrochemical enterprises in the new equilibrium state is n5-n7 (odd number)-n6-n8 (even number). It means that the surviving odd number petrochemical enterprises will become the bigger petrochemical enterprises, the survival even number ones will become the smaller. It is a significant symmetrical strong and weak distribution law for petrochemical enterprises, which will be further studied.

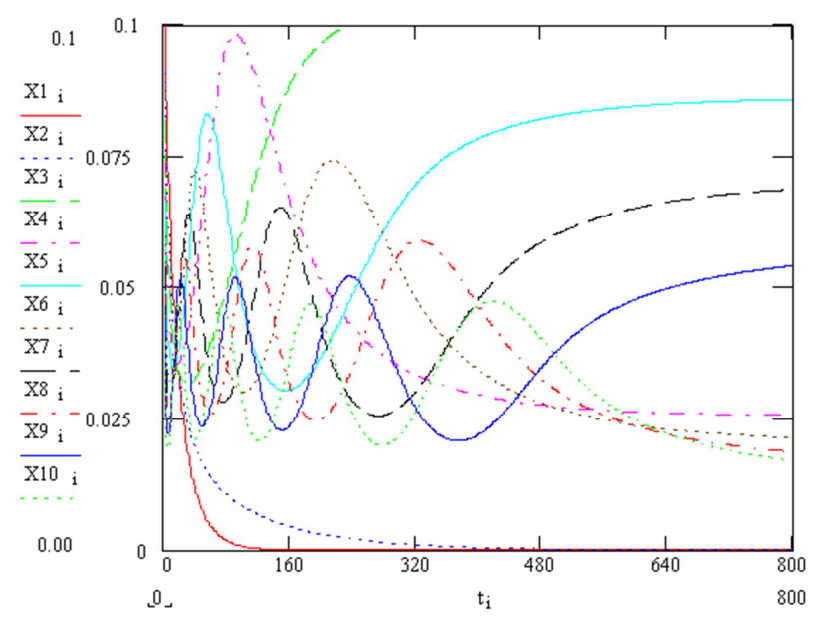

(a)

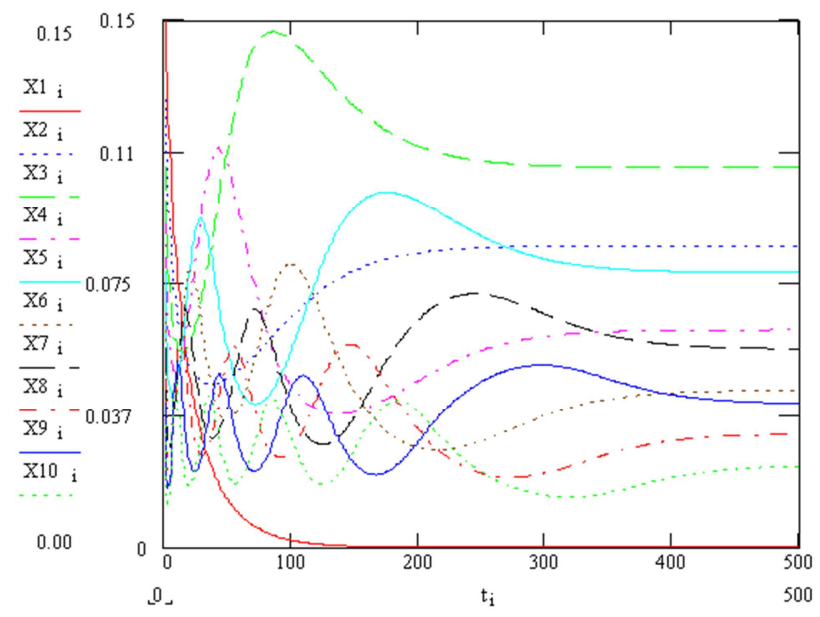

(b)

Figure 2. How petrochemical enterprises respond and adapt to petroleum shortage. Here $X$ stands for the occupancy $P$ of refineries to petroleum market. $n=10, D=0.3, m=0.02$. (a) $q=0.1$; (b) $q=0.15$. 
In order to further explain the dynamic characteristic for the petrochemical enterprises adaptation to the petroleum shortage and their responds, we give the result for $n=10$, $D=0.3$, q taking 0.1 and 0.15 respectively (to correspond to the different petrochemical system structure). as Figure $2 \mathrm{a}-\mathrm{b}$.

From Figure $2 \mathrm{a}-\mathrm{b}$ and Figure 1: (1) Under premise of $D>q$, the larger the value of $D / q$ is, the more the number of petrochemical enterprises that go decline as a result of petroleum shortage. When $D / q=0.3 / 0.1=3$, the first two big petrochemical enterprises in the system will fully go decline in turn, but when $D / q=0.3 / 1.5=2$, only the biggest petrochemical enterprise $\mathrm{n} 1$ in the system will go decline. (2) Passing through multi-equilibrium state of coexistence and the continual replacement of the biggest petrochemical enterprise, the system comes to a new equilibrium state. During this time, the strong and weak international petrochemical enterprises will strictly observe the even-odd number symmetrical law or the odd - even number symmetrical law. If the petroleum shortage leads to odd number of petrochemical enterprises going decline, then after adaptation and stability, the petrochemical enterprises whose original sequence number is even will get stronger, but the one whose original sequence number is odd will become weaker. For example, when $D / q$ $=0.3 / 0.1=3$, the first two petrochemical enterprises in the system will go decline, then at the new equilibrium state, the order from strong to weak is $\mathrm{n} 3 \rightarrow \mathrm{n} 5 \rightarrow \mathrm{n} 7 \rightarrow \mathrm{n} 9 \rightarrow \mathrm{n} 4 \rightarrow \mathrm{n} 6 \rightarrow \mathrm{n} 8 \rightarrow \mathrm{n} 10 . \quad$ When $\quad D / \quad q$ $=0.3 / 0.15=2$, the biggest petrochemical enterprise in the system will go decline, then the new equilibrium state order from strong to weak is $\mathrm{n} 2 \rightarrow \mathrm{n} 4 \rightarrow \mathrm{n} 6 \rightarrow \mathrm{n} 8 \rightarrow \mathrm{n} 10 \rightarrow \mathrm{n} 3 \rightarrow \mathrm{n} 5 \rightarrow \mathrm{n} 7 \rightarrow \mathrm{n} 9$.

\subsection{Mathematical Derivation and Theoretical Analysis}

Supposing the shortage ratio of the international petroleum market and resource is $D$, then, after a certain time, the surviving petrochemical enterprises reach a new balance. The occupancy $p_{i}{ }^{e}\left(d_{\mathrm{i}} / d t=0\right)$ of all the different petrochemical enterprises in the international petroleum market is the stationary state solution of (1):

$$
p_{i}^{e}=\left\{\begin{array}{l}
\hat{p}_{i} \quad \text { if } \quad \hat{p}_{i}>0 \quad\left(\hat{p}_{i}=1-D-\frac{m_{i}}{c_{i}}-\sum_{j=1}^{i} p_{j}^{e}\left(1+\frac{c_{j}}{c_{i}}\right) \quad i=1,2 \ldots n\right. \\
0 \quad \text { if } \quad \hat{p}_{i} \leq 0
\end{array}\right.
$$

Obviously, when

$$
D \geq 1-m_{i} / c_{i}=1-(1-q)^{2 i-1}
$$

The first $i$ strong petrochemical enterprises in this petrochemical system will go decline.

The formula (4) is the critical binding relation among the decline number of the big petrochemical enterprise, the petroleum shortage ratio and the petroleum market occupancy of the biggest petrochemical enterprise.

Figure 3 discloses the relation between the decline number of big petrochemical enterprise and the petroleum shortage ratio under the critical binding condition $D=1-(1-q)^{2 i-1}$.
The four winding lines respectively correspond to the four kinds of petrochemical enterprise conditions: $q=0.02,0.05$, 0.1 , and 0.3 . In it, $q=0.1$ means that the biggest international petrochemical enterprise occupies $10 \%$ of the international petroleum resource market. The petroleum occupancy of the second biggest petrochemical enterprise is $\left.\mathrm{p}_{2}\right|_{\mathrm{D}=0}=0.1$ $(1-0.1)^{2-1}=0.09=9 \%$, That of the third biggest one is $\left.\mathrm{p}_{3}\right|_{\mathrm{D}=0}=0.1$ $(1-0.1)^{3-1}=0.081=8.1 \%, \cdots$. But $q=0.03$ means the international petroleum resource market occupancy of the biggest petrochemical enterprise is $3 \%$. The petroleum occupancy of the second biggest one is $\left.\mathrm{p}_{2}\right|_{\mathrm{D}=0}=0.03$ $(1-0.03)^{2-1}=0.029=2.9 \%$, That of the third biggest one is $\left.\mathrm{p}_{3}\right|_{\mathrm{D}=0}=0.03(1-0.03)^{3-1}=2.8 \%, \cdots$. Looking from Figure 3 , we can see when $D$ (petroleum shortage) takes a certain value, the larger the $q$ is, the smaller the decline number will get as result of petroleum shortage.

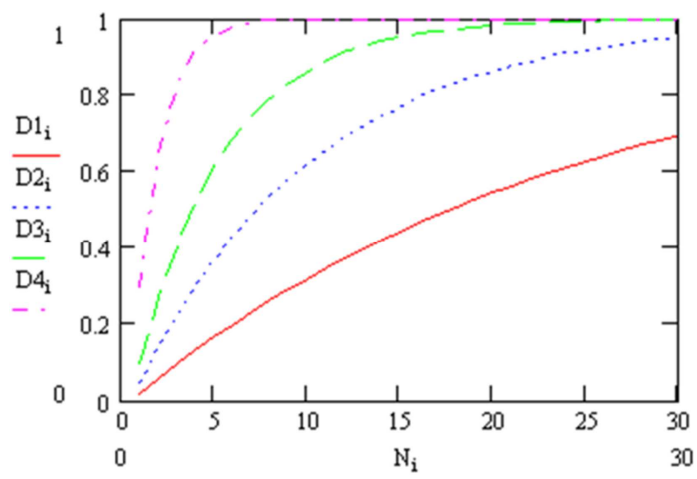

Figure 3. The relationship between the decline number of petrochemical enterprises and the petroleum shortage ratio under the critical decline binding condition $D=1-(1-q)^{2 i-1}$. The four winding lines respectively correspond to four kinds of distribution structure of petrochemical enterprise: $q=0.02,0.05,0.1,0.3$.

Table 1 gives the critical binding relation among the decline number (n) of the big petrochemical enterprise, the petroleum shortage ratio $(D)$ and the petroleum market occupancy of the biggest petrochemical enterprise $(q)$.

Table 1. The relationship between the international petroleum shortage (D) and the petrochemical enterprise decline number (n) for different values of $q$

\begin{tabular}{lllllll}
\hline $\mathbf{D}$ & $\boldsymbol{q}=\mathbf{0 . 0 1}$ & $\boldsymbol{q}=\mathbf{0 . 0 2}$ & $\boldsymbol{q}=\mathbf{0 . 0 5}$ & $\boldsymbol{q}=\mathbf{0 . 1}$ & $\boldsymbol{q}=\mathbf{0 . 1 5}$ & $\boldsymbol{q}=\mathbf{0 . 2}$ \\
\hline $\mathrm{n}=1$ & 0.01 & 0.02 & 0.05 & 0.1 & 0.15 & 0.2 \\
$\mathrm{n}=2$ & 0.03 & 0.059 & 0.143 & 0.271 & 0.386 & 0.488 \\
$\mathrm{n}=3$ & 0.049 & 0.096 & 0.226 & 0.41 & 0.556 & 0.672 \\
$\mathrm{n}=4$ & 0.068 & 0.132 & 0.302 & 0.522 & 0.699 & 0.79 \\
$\mathrm{n}=5$ & 0.086 & 0.166 & 0.37 & 0.613 & 0.768 & 0.866 \\
$\mathrm{n}=6$ & 0.105 & 0.199 & 0.431 & 0.686 & 0.833 & 0.914 \\
$\mathrm{n}=7$ & 0.122 & 0.231 & 0.487 & 0.746 & 0.879 & 0.945 \\
$\mathrm{n}=8$ & 0.146 & 0.261 & 0.537 & 0.794 & 0.913 & 0.965 \\
\hline
\end{tabular}

Table 1 explains that as the biggest petrochemical enterprise gets weaker, the minor petroleum shortage ratio $D=q=0.05$ will lead it to decline; but the resistance of $n 2, n 3, n 4$ nonlinearly increases in turn. For instance, when $D$ adds to 6 times, n4 will go decline $(D=0.302)$.

It is necessary to point out that the conclusion from table 1 is one-sided. We will show how petroleum shortage leads to the decline of small petrochemical enterprises in next study. 


\section{Application}

Because of the global oil reserves are being detected, we use global annual actual oil production data as the basis of the model calculation. The global petroleum outputs in 1993 was 3765764 kilo tons, $0.474 \%(D)$ less than 3781844 kilo tons in 1992. The outputs and the corresponding positions of first global 18 petrochemical enterprises are showed as the following table 2 [17-18]. By calculation, we discovered the yields from the second to the eighteenth enterprises basically are in accordance with geometric series of $p=q(1-q)^{i-1}$. Then we have the results in column 4 of table 2 , which exactly corresponds to the factual conditions given in column 3 . As a result, we take: $m_{i}=m, p=q(1-q)^{i-1}, c_{i}=m_{i} /(1-\mathrm{q})^{2 i-1}$. Obviously, Royal Dutch/Shell (the first position) and Exxon (the second position) yield much higher and their places are assured in 2 or 3 years, so in the first five years, the model is simulated only from the third firm to the eighteenth one with factual data as parameters:

$q=207890 / 3781844=0.055$ (the petroleum occupancy of
Royal
Dutch/Shell
in
1992),

$D=(3781844-3765764) / 3781844=0.474 \%$ (according to the model (2)). The results are demonstrated as figure 4.

The simulation results show that positions change between the third firm PDVSA and the fourth one SINOPEC in about one year (350 days), and after about 5 years (1800 days), the eighteenth firm KNPC rides up to the seventeenth. Conveniently, we take 3 years as the period, and then the figure 4 stands for the petroleum occupancy (i.e. orders) from the first firm to the eighteenth one in 1995. The table 2 gives the factual orders [19] in column 5 and the simulated orders in column 6 , obviously, the simulation basically corresponds to the facts, especially the predicted trend (rise or fall in position) with the accuracy reaching $14 / 18=78 \%$.

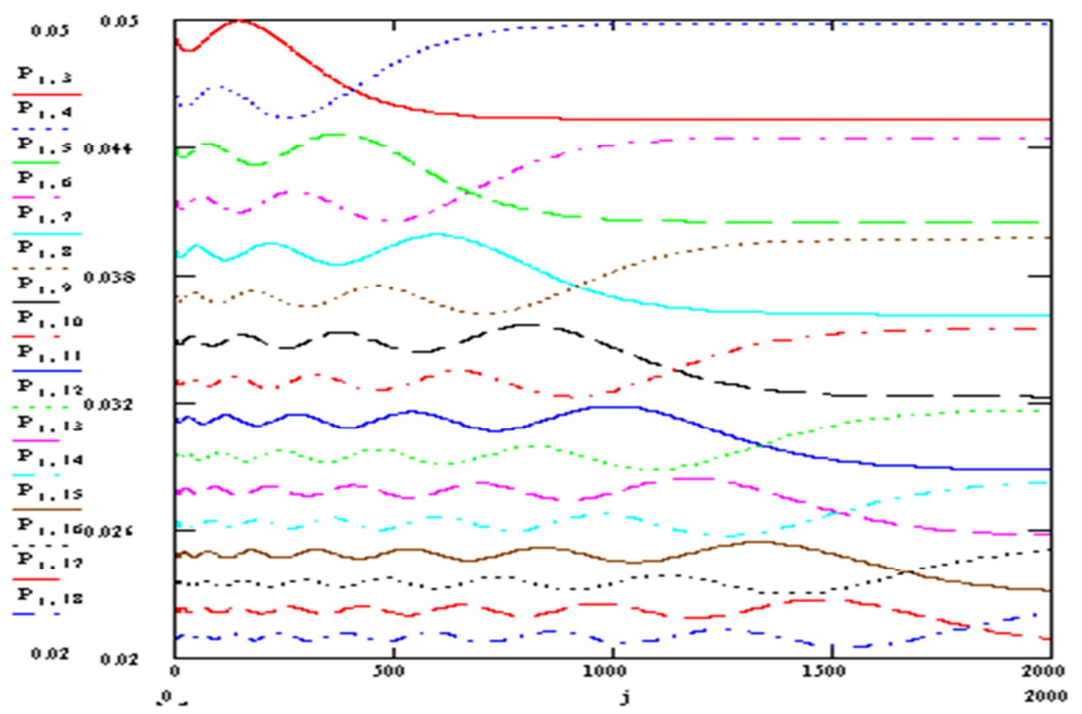

Figure 4. The evolution simulations from the third to the eighteenth big petrochemical enterprises.

Table 2. The order and the prediction of the first 18 petrochemical enterprises from 1992 to 2012.

\begin{tabular}{|c|c|c|c|c|c|c|c|c|c|c|}
\hline $\begin{array}{l}\text { Order } \\
(1992)\end{array}$ & Company & $\begin{array}{l}\text { The Output } \\
\text { Value (KT/Y) } \\
\text { (1992) }\end{array}$ & $\begin{array}{l}\text { The Calculated } \\
\text { Value }(\mathrm{KT} / \mathrm{Y}) q_{i}\end{array}$ & $\begin{array}{l}\text { The } \\
\text { Order } \\
\text { (1995) }\end{array}$ & $\begin{array}{l}\text { The Predicted } \\
\text { Order (1995) }\end{array}$ & $\begin{array}{l}\text { The Trend } \\
(1992-1995)\end{array}$ & $\begin{array}{l}\text { The } \\
\text { Predicted } \\
\text { Trend }\end{array}$ & $\begin{array}{l}\text { The Output } \\
\text { Value (KT/Y) } \\
\text { (2012) }\end{array}$ & $\begin{array}{l}\text { The } \\
\text { Order } \\
(2012)\end{array}$ & $\begin{array}{l}\text { The Predicted } \\
\text { Trend (2012) }\end{array}$ \\
\hline 1 & $\begin{array}{l}\text { Royal } \\
\text { Dutch/Shell }\end{array}$ & 207890 & & 1 & & & & 83300 & 15 & $9 \downarrow$ \\
\hline 2 & Exxon & 179120 & 175500 & 2 & & & & 115600 & 9 & $7 \downarrow$ \\
\hline 3 & PDVSA & 149000 & 156800 & 4 & 4 & $\uparrow$ & $\uparrow$ & 125000 & 7 & $6 \downarrow$ \\
\hline 4 & SINOPEC & 147500 & 140000 & 3 & 3 & $\downarrow$ & $\downarrow$ & 149400 & 3 & $10 \downarrow$ \\
\hline 5 & Mobil & 110500 & 125000 & 5 & 6 & & & \multicolumn{3}{|c|}{ Exxon and Mobil Merge in 1999} \\
\hline 6 & Chevron & 98300 & 111600 & 9 & 5 & $\downarrow$ & $\uparrow$ & 92450 & 13 & $4 \uparrow$ \\
\hline 7 & $\mathrm{BP}$ & 98220 & 99700 & 6 & 8 & $\uparrow$ & $\downarrow$ & 107850 & 11 & $8 \downarrow$ \\
\hline 8 & Pemex & 81600 & 89030 & 7 & 7 & $\uparrow$ & $\uparrow$ & 143850 & 5 & $1 \uparrow$ \\
\hline 9 & $\begin{array}{l}\text { Texaco } \\
\text { (Chevron) }\end{array}$ & 78900 & 79510 & 11 & 10 & $\downarrow$ & $\downarrow$ & \multicolumn{3}{|c|}{$\begin{array}{l}\text { Texaco bought by Chevron for } \$ 39 \text { billion } \\
\text { In } 2001\end{array}$} \\
\hline 10 & Aramco & 74020 & 71000 & 8 & 9 & $\uparrow$ & $\uparrow$ & 516550 & 1 & $5 \uparrow$ \\
\hline 11 & Petrobras & 61680 & 63410 & 10 & 12 & $\uparrow$ & $\downarrow$ & 108500 & 10 & $13 \downarrow$ \\
\hline 12 & NIOC & 55830 & 56620 & 12 & 11 & & & 216050 & 2 & $11 \uparrow$ \\
\hline 13 & Amoco (BP) & 4920 & 50570 & 13 & 14 & & & \multicolumn{3}{|c|}{$\begin{array}{l}\text { Amoco was acquired by BP for } \$ 27.6 \\
\text { billion In } 1998\end{array}$} \\
\hline 14 & ENI (AGIP) & 46650 & 45160 & 14 & 13 & & & 42250 & 26 & $12 \uparrow$ \\
\hline 15 & TOTAL & 45530 & 40330 & 16 & 16 & $\downarrow$ & $\downarrow$ & 61300 & 18 & $16 \downarrow$ \\
\hline 16 & Pertamina & 43010 & 36010 & 17 & 15 & $\downarrow$ & $\uparrow$ & 9600 & 54 & $15 \uparrow$ \\
\hline 17 & $\begin{array}{l}\text { Idemitsu } \\
\text { Kosan }\end{array}$ & 38900 & 32160 & 18 & 18 & $\downarrow$ & $\downarrow$ & \multicolumn{2}{|c|}{$\begin{array}{l}\text { Fell out of the } \\
\text { top } 50\end{array}$} & $18 \downarrow$ \\
\hline 18 & KNPC & 37800 & & 15 & 17 & $\uparrow$ & $\uparrow$ & 145050 & 4 & $17 \uparrow$ \\
\hline
\end{tabular}


If the time is extended to 2012 for 20 years long, how the simulation results will change. The 18 big oil companies are affected by many factors, such as the resource factors and the social and economic factors in 20 years. Therefore, according to the value of $D$ actual fluctuations, the initial value of $D$ will be adjusted every 5 years. According to the actual world oil production data $[17,20]$, during the second five year period (1998-2002, 1800-3600 time period in Figure 5), in 1998, $D=(3529.1-3451.8) / 3529.1=0.0219, \quad \mathrm{q}=0.056208$ which is obtained based on the data at the end from the first five year period. During the third five years (2003-2007, 3600-5400 time period in Figure 5), in 2003, $D=(3869.7-3695.1) / 3869.7=0.047252, \mathrm{q}=0.072153$ which is obtained based on the mantissa during the second five years. During the fourth five year period (2008-2012, 5400-7200 time period in Figure 5), in 2008, $D=(3934.7-3820.5) / 3934.7=0.02902, \quad \mathrm{q}=0.075106$ which is obtained on the basis of the mantissa in the third five year period.

In order to analyze easily the trend of 18 big oil companies for 20 years, we combined the simulation curves of four time period into Figure 5 (1992-2012). As shown from simulation results (Table 2 eleventh column and Figure 5), the simulating trend of these 5 companies is inconsistent with the actual trend (ranking rise or fall), and the false is of $5 / 18=27.8 \%$, on the contrary, the accurate rate is $13 / 18=72.2 \%$.

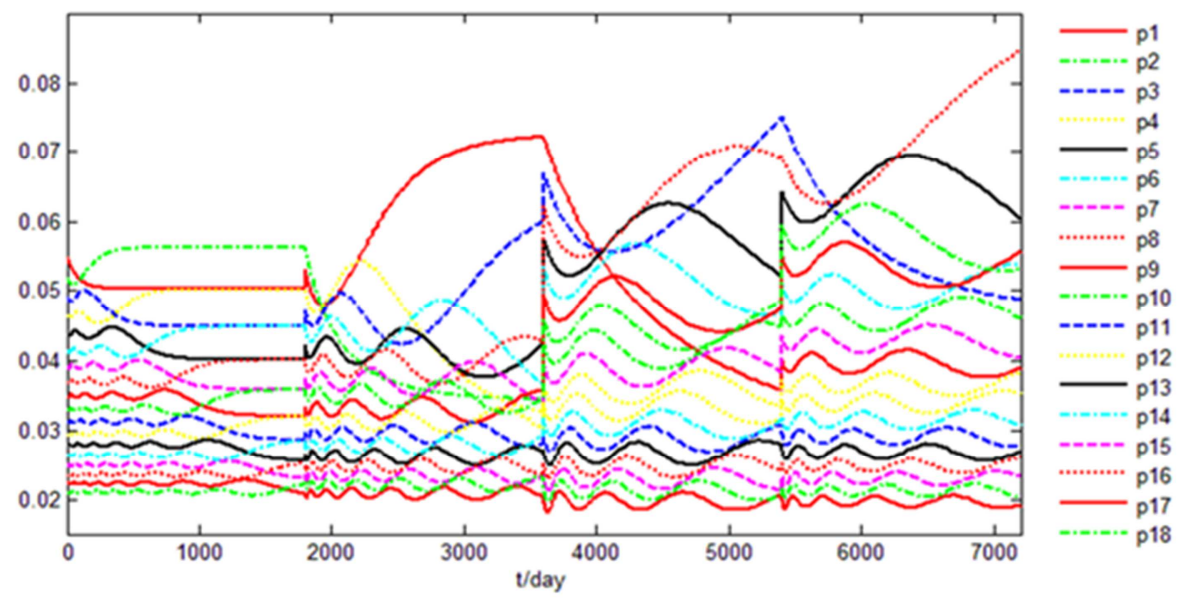

Figure 5. The composition trend graph of the 18 big oil companies for four time segment (1992-2012) (the initial value of D is adjusted every 5 years. 1800, 3600, 5400 which are the joints of four time periods, the change of initial value of D lead to the curve trend mutation, which does not affect the simulation results).

\section{Conclusions}

We have used mathematical simulate analysis and example verification and systematically studied the enterprise decay dynamics mechanism and constraint relation for petrochemical enterprises in different case of shortage of resources. The results show that in the circumstance of $\mathrm{D}>\mathrm{q}$, which refer as resource shortage rate is greater than resource share rate of the strongest enterprise in enterprise community, petrochemical enterprises evolution under the global resources market economy has the following rules and characteristics:

(1) The dominant species (strong) enterprise n1 will inevitably decline and undergo transformation in the petrochemical enterprises community. With the resource shortage rate increased, the weaker enterprises will decline along with the strongest enterprises. The larger value of $\mathrm{D} / \mathrm{q}$ comes with more decline of strong enterprise in community. When the strongest enterprises $\mathrm{nl}$ is weak in the resource-based petrochemical enterprises community (q minor), the small disturbance resources (shortage) can cause it to decline and even transform. But the resistance of n2, n3, n4 is increasing nonlinearly in turn. While $\mathrm{q}$ is large, $\mathrm{n} 3, \mathrm{n} 4 \ldots \ldots$. will not decline under the condition of the shortage of resources, which means that the large enterprises in petrochemical enterprises system come stronger. When resources shortage appears, the small petrochemical enterprises have stronger resilience and adaptability, so they can adapt to new petroleum situation quickly and survive from getting drowned.

(2) The surviving petrochemical enterprises after the resources shortage in the community will experience three stages of evolution: (1) resistance stage: the occupy ratio of each petrochemical enterprises in the international petroleum resource market will go down. But the weakest company declined minimally, namely the weakest enterprises in the petrochemical enterprise community have relatively stronger resistance. (2) resumption stage: all but the biggest enterprises in the petrochemical system will gain more market share and thus move to higher position in order from the smallest, the second smallest..., which shows that the position occupied by petrochemical enterprise changes frequently. (3) stable stage: after a series of re-arrangements, the international petrochemical enterprise system will reach a new equilibrium state. The international petrochemical industry will strictly observe the even-odd or odd-even number symmetry law. If the shortage of petroleum leads to the decline of odd-number petrochemical enterprises, after the adaptability and stability, the petrochemical enterprise system will obey the even-odd number symmetry law, i.e. the former ordinal number petrochemical enterprises become 
bigger. If the decline petrochemical enterprise in this system is ranked even-number, after the adaptability and stability, the petrochemical enterprise will obey the odd-even number symmetry law, i.e. the former odd numbered petrochemical enterprise become bigger, but those former even numbered get smaller.

We think that only if petrochemical enterprises learn the international petroleum shortage ratio and the occupancy of the biggest enterprise in the petroleum resource market, understand the even-odd or odd-even symmetrical law in the petroleum economical system and position themselves correctly can they become stronger and stronger.

\section{Funding}

This work was supported by Jiangxi University Humanities and Social Sciences Research Project of China [No. JC18118], and the Humanity and Social Sciences Foundation of Ministry of Education of China (17YJAZH113).

\section{References}

[1] Editorial Group of Millionaire History of China Petroleum Industry. Millionaire History of China Petroleum Industry. Beijing: Contemporary China Press. 2002.

[2] Li Yueqing. The First Class In The World-A Deep Perspective On The Core Connotation And Basic Path Of China's Petroleum And Petrochemical Enterprises In Pursuit Of High Quality Development. China Petroleum Enterprise, 2018, 3: 48-50.

[3] Zhao Xiao-li. Research on Sustainable Development Countermeasures of Resource-Based Enterprises. Management \& Technology of SME, 2020 (7): 143-144.

[4] Saha; Pranesh Chandra. Sustainable energy development: a challenge for Asia and the Pacific region in the 21st century. Energy Policy, 2003, 31 (11), 1051-1059.

[5] Mu Xuejiang. Management innovation closely follows the pulse of the times--2017 "National Review on the Management Innovation of National Petroleum and Petrochemical Enterprises" highlights the trend of management innovation. China Petroleum Corporation, 2017 (10): 38-45.

[6] Sun Yinghe. Opportunities and challenges facing the operation and management of petrochemical enterprises under the new situation. Chemical management, 2017 (5): 93-94.
[7] Wang Xiaojian. Opportunities and challenges facing the management of oil companies under the new situation. Modern State-owned Enterprise Research, 2016, 04: 93.

[8] Wang B A. On the Evaluation of the Green Competitiveness of the Petrochemical Enterprises in China-Taking a Petrochemical Enterprise as an Example. Technoeconomics \& Management Research, 2015 (8): 67-70.

[9] Miu Lei. Intrinsic Relationship between Resource Consumption and Sustainable Development of Enterprise: Complex System Theory. REFORMATION \& STRATEGY, 2015, 31 (9): 42-46.

[10] Wang Delu, Tong Xian, Wang Yadong. An early risk warning system for Outward Foreign Direct Investment in Mineral Resource-based enterprises using multi-classifiers fusion. Resources Policy, 2020, 66. DOI: 10.1016/j.resourpol.2020.101593.

[11] Chow; Larry C. H. Themes in current Asian energy. Energy Policy, 2003, 31 (11), 1047-1049.

[12] JIA Wen-rui, et al. Energy, Environment and Petroleum Industry Development in China in the 21st Century. Beijing: Petroleum Industry Press. 2002.

[13] Giot; Pierre; Laurent; Sébastien. Market risk in commodity markets: a VaR approach. Energy Economics 2003, 25 (5), 435-457.

[14] Cao Yu. Research on the Strategy of Improving Green Competitiveness of Resource-based Enterprises. Corporate Strategy, 2017 (10): 146-149.

[15] Tilman, D.; R. M. May; C. L. Lehman; and M. A. Nowak. Habitat destruction and the extinction debt. Nature 1994, 371, 65-66.

[16] Lin Zhen-Shan. Simulatinf unintended effects restoration. Ecological Modelling 2003, 164, 169-175.

[17] The Committee of The Yearbook of the Word Economic (China). The Yearbook of the Word Economic (1992-1993), The Science Press of China. 1993-1994.

[18] The Committee of The Yearbook of the Word Economic (China). The Yearbook of the Word Economic (2012), The Science Press of China. 2013.

[19] The Committee of The Yearbook of the Word Economic (China). The Yearbook of the Word Economic (1995), The Science Press of China. 1996.

[20] The Committee of The Yearbook of the Word Economic (China). The Yearbook of the Word Economic (1998-2011), The Science Press of China. 1999-2012. 